БАРАНОВА Татьяна Владимировна - аспирант кафедры истории и теории международных отношений Нижегородского государственного университета им. Н.И. Лобачевского (603950, Россия, г. Нижний Новгород, ул. Ульянова, 2; sky-ellize@yandex.ru)

КРИВОВ Сергей Валерьевич - кандидат исторических наук, доцент кафедры политологии Нижегородского государственного университета им. Н.И. Лобачевского (603950, Россия, г. Нижний Новгород, ул. Ульянова, 2; skrivov2@уаndex.ru)

УСТИНКИН Сергей Васильевич - доктор исторических наук, профессор; директор Приволжского филиала ФНИСЦ РАН (603000, Россия, г. Нижний Новгород, Холодный пер., 4); начальник международной междисциплинарной научно-исследовательской лаборатории изучения мировых и региональных социально-политических процессов Нижегородского государственного лингвистического университета им. Н.А. Добролюбова; научный руководитель Высшей школы международных отношений и мировой политики Нижегородского государственного лингвистического университета им. Н.А. Добролюбова (603950, Россия, г. Нижний Новгород, ул. Минина, 31a; sv.ustinkin@gmail.com)

\title{
МИГРАЦИЯ В ДИСКУРСЕ ИЗБИРАТЕЛЬНОЙ КАМПАНИИ 2013 г.: ПОПУЛИЗМ ИЛИ ИДЕОЛОГИЧЕСКАЯ ТРАНСФОРМАЦИЯ?
}

\begin{abstract}
Аннотация. В статье рассматривается избирательная кампания мэра Москвы 2013 г. с точки зрения использования ее участниками в ходе предвыборной гонки приемов и методов популистского дискурса. В качестве исследовательского метода применяется дискурсивный подход Э. Лакло, нацеленный на выявление базовых индикаторов популистской риторики. Анализ рассматриваемого материала позволяет сделать выводы об усилении популистской риторики в российском политическом дискурсе на фоне падения электоральных результатов кандидатов, представляющих традиционные российские партийноидеологические платформы.
\end{abstract}

Ключевые слова: популизм, дискурс идентичности, иммиграция, избирательная компания, электорат

$\mathrm{B}$ июне 2013 г. было объявлено о прямых выборах мэра Москвы, в ходе которых ключевой темой стала проблема иммиграции, оживившая дискурс идентичности в российском обществе. Ранее, в октябре 2010 г., после конфликта с Ю. Лужковым, занимающим должность мэра с 1992 по 2010 г., президент Д. Медведев назначил вице-премьера и бывшего главу администрации президента С. Собянина новым руководителем столицы. Когда в 2012 г. были восстановлены прямые выборы глав регионов, Собянин не стал дожидаться истечения срока полномочий в 2015 г. и 5 июня 2013 г. обратился к президенту В. Путину с официальной просьбой освободить его от обязанностей, чтобы идти на досрочные выборы. Путин в ответ назначил его исполняющим обязанности мэра, а через два дня Мосгордума официально приняла решение о проведении выборов 8 сентября 2013 г. ${ }^{1}$

Такой шаг объяснялся необходимостью получения мандата доверия для укрепления авторитета мэрии, а сам Собянин в интервью «Московским новостям» пояснил: «Человек, которого поддержали избиратели, который пользуется мандатом, основанным на доверии, может быстрее и эффективнее реализовать свои планы и программы» 2 . Кроме того, после выборов в Государственную

1 Путин подписал указ об отставке Собянина. - Ведомости. 05.06.2013. Доступ: https:// www.vedomosti.ru/politics/articles/2013/06/05/putin_prinyal_otstavku_sobyanina (проверено 08.09.2021).

2 Богомолов А., Николаева А. Нужны и демократия, и власть. - Московские ведомости. 30.05.2013. Доступ: https://www.mn.ru/moscow_authority/20130530/347635870.html (проверено 08.09.2021). 
думу в декабре 2011 г. прошла волна масштабных публичных выступлений, а различные части несистемной оппозиции создали координационный совет, объединявший разные по идеологии организации - националистов, либералов, левых, а также гражданских активистов в целом. Однако к июню 2013 г. протестный потенциал заметно снизился, уменьшив вероятность негативного фона вокруг предвыборной кампании.

Наряду с Собяниным, наиболее заметной фигурой в избирательной гонке стал А. Навальный - один из лидеров протестного движения 2011-2012 гг., которого выдвинула Республиканская партия России - Партия народной свободы (РПР-ПАРНАС), считавшаяся сторонницей западного либерализма. Однако взгляды самого А. Навального были более сложными. Его антикоррупционная риторика обеспечивала симпатии со стороны либералов, а как националист он участвовал в создании организации «НАРОД» еще в 2007 г., а также активно поддерживал кампании «Хватит кормить Кавказ» и Движение против нелегальной миграции (ДПНМ). Навальный несколько раз участвовал в «Русском марше», оправдывая это тем, что его повестка дня отражает реальные проблемы многих простых консервативно настроенных граждан ${ }^{1}$. Согласно официальной биографии, он скорее либерал с националистическими убеждениями, чем националист с демократическими идеями [Воронков 2012]. Хотя Г. Голосов утверждает, что его предполагаемый национализм всегда был «довольно сомнительным» [Golosov 2013], а Э. Паин, изучив более 1300 постов Навального в «Живом журнале» за три года до выборов, обнаружил, что только 40 из них были посвящены этнополитическим вопросам [Паин 2013].

Остальные конкуренты были кандидатами от различных политических партий. Так, ЛДПР сделала выбор в пользу молодого 32-летнего политика Михаила Дегтярева, депутата Госдумы от Самары. КПРФ выдвинула Ивана Мельникова, профессора МГУ и депутата пяти Госдум подряд, в то время занимавшего пост первого вице-спикера Думы, а «Справедливая Россия» и «Яблоко» - своих партийных лидеров: петербуржца Николая Левичева и коренного москвича Сергея Митрохина.

В ходе избирательной кампании было выявлено несколько проблем, волновавших столичного избирателя: трудности в транспортном секторе, проблемы на рынке жилья, качество и доступность медицинских услуг. Однако больше всего москвичей, по-видимому, беспокоил рост числа мигрантов в столице. Весной 2013 г. «Первый канал» и «Россия» широко обсуждали вопросы, связанные с иммигрантами, а согласно опросу ряда социологических центров, включая Левада-Центр, мигранты составляли главную проблему, стоящую перед городом

Целью данной статьи является попытка выявления популистских практик, используемых участниками избирательной гонки, путем дискурсивного анализа предвыборной риторики в отношении миграционной политики.

\section{Теоретические аспекты изучения популистского дискурса}

Содержание понятия «популизм», как правило, затрагивает широкий по охвату спектр проблем. Сами популисты заявляют, что представляют большинство «простых людей» [Canovan 1999], а их риторика часто претендует

\footnotetext{
1 «Русский марш». А. Навальный. - LiveJournal. 02.11.2013. Доступ: http://navalny. livejournal.com/877154.html (проверено 30.06.2021).

2 Москва накануне выборов мэра: полное исследование. - Левада-Центр. 17.07.2013. Доступ: https://www.levada.ru/2013/07/17/moskva-nakanune-vyborov-mera-polnoeissledovanie/ (проверено 08.09.2021).
} 
на некое искупление перед народом - вернуть власть, представить реальные интересы народа и т.д. Центральным элементом здесь является понятие «народ», или так называемая внутренняя группа (in-group), содержание которого на самом деле довольно расплывчато и может быть понято только с помощью дискурсивного анализа или в рамках определенного смыслового контекста.

Согласно широко распространенному постмарксистскому подходу, истинные популисты, как правило, позиционируют в качестве «народа» те общественные группы, которые недостаточно представлены в составе правящих групп (истеблишмента), а возможно, даже и находящиеся в конфликте с ними. Фактически речь идет о «политизации идентичности», поскольку те, кто из-за своего класса, религии, этнической или территориальной принадлежности имел ущемленное положение, признаются в качестве полноправных политических субъектов.

Важной частью такой политики является указание на существующие или мнимые противоречия с так называемой внешней группой («другие»). Классическими примерами «другого» являются правящие группы, политический истеблишмент или интеллектуальные элиты [Rydgren 2006]. Однако это могут быть и представители более широких слоев населения. Например, популистская антииммиграционная партия может определить в качестве внутренней группы «добропорядочное коренное население», указывая одновременно на внешнюю группу - иммигрантов - и на их негативные характеристики. К «другим» также могут быть отнесены лица независимо от их этнического происхождения, выступающие с проиммигрантских и проинтеграционистских позиций. При этом важным моментом для популизма является создание антагонизма [Laclau 2005], т.е. такого противоречия, которое не может быть преодолено путем компромисса и выражается в диалектике постоянной борьбы противоположностей. При этом отличие умеренных популистов от радикальных состоит в мерах, предлагаемых против «других»: более умеренные могут просто использовать антагонизм для мобилизации сторонников и применения оппозиции в качестве раскола, в то время как радикалы, предлагая меры по устранению «другого», выступают против любого вида социального плюрализма.

Важной частью популистской проблематики является понятие хартленда по словам П. Таггарта [Taggart 2004], особого места во времени и пространстве, в той или иной степени соответствующего историческим фактам и использующегося для создания сообщества или эмоциональной связи (Москва для москвичей). Другими словами, это инструмент для построения повествования, а принимая во внимание двойственную природу формирования идентичности, у него может быть и обратная сторона - антихартленд, или момент во времени и пространстве, который изображается как негативный (например, «темное советское прошлое» или «империя зла»).

Наконец, популизм также имеет свои особенности в способах и манере осуществления политических практик. Несмотря на то что пока нет четкого концептуального видения относительно сущности популистской политики и ее границ, в исследовательской литературе есть примеры сфер политики, чаще всего связанных с популизмом. Среди них требования внесения радикальных изменений в политическую систему [Canovan 1999], политика перераспределения благ [Taggart 2004], конкретные изменения в налогообложении или денежной системе [Rydgren 2006], а также вопросы миграции и другие сферы этнической политики. При этом ни одну из них нельзя назвать исключительно популистской сферой. Скорее речь идет о масштабах, качестве и проработан- 
ности отдельных политических предложений, а также о политической программе акторов в целом.

Таким образом, для определения популистской направленности анализируемых избирательных кампаний необходимо рассмотреть базовые индикаторы дискурсивного повествования: использование дихотомии «свои - другие», придание ей антагонистического характера в виде наличия непреодолимых противоречий между ними, использование символической пространственновременной характеристики (хартленд) как инструмента мобилизации электората и, наконец, выбор способов и манеры политических практик, исходя из имеющейся концептуализации понятия «популистская политика».

\section{Проблема мигрантов в российском политическом дискурсе}

Накануне президентских выборов 2012 г. В. Путин опубликовал в «Независимой газете» статью «Россия: национальный вопрос» 1 , содержащую утверждение, что российский процесс формирования государства уникален тем, что «у нас многонациональное общество, но единый народ». При этом этнические русские составляют «государствообразующую нацию» в рамках этого сообщества: «То, что соткало ткань этой уникальной цивилизации, - это [этнический] русский народ, русская культура». Следовательно, при сохранении традиционной государствоцентричной ориентации в русле имперского и советского, а также постсоветского гражданского (россияне) понимания нации, Путин прямо заявил, что «русскость» является ядром национальной идентичности. Это, естественно, порождает вопрос о ее внешних границах и ставит проблему «чужого» («другого»).

Хотя после событий 2014 г. понятие «Запад» стало более значимым проявлением инаковости (противостоящее «другое»), понятие «мигранты» по-прежнему занимает центральное место в этом дискурсе 2 . В вышеупомянутой статье Путин уделил значительное место миграционной проблеме, признав, что многие люди серьезно обеспокоены нынешними тенденциями, указав на необходимость борьбы с нелегальной иммиграцией. Тем не менее его основной посыл касался необходимости «цивилизованной интеграции и социализации» мигрантов: «Важно, чтобы мигранты могли нормально адаптироваться в обществе». В соответствии со своим в целом русскоцентричным подходом он пришел к выводу, что, как минимум, следует ожидать, что мигранты научатся говорить по-русски и адаптируются к русской культуре. Также подчеркивались различия между легальной и нелегальной, а также внешней и внутренней миграцией.

Следует отметить, что в повседневном российском дискурсе термин «мигрант» часто используется для обозначения членов определенных этнических и региональных сообществ. Согласно Э. Паину, «в Москве никто не называет мигрантом “ни петербуржца, ни жителей Орла, ни Тюмени, ни татар, ни башкир из своих республик - на самом деле даже выходцы из Украины и Белоруссии могут избежать этого эпитета"» 3 . Термин «мигрант» используется преимущественно для людей, прибывающих с Кавказа, как с Северного, так и с

1 Путин В. Россия: национальный вопрос. - Независимая газета. 23.01.2012. Доступ: https://www.ng.ru/politics/2012-01-23/1_national.html (проверено 01.07.2021).

2 В.И. Мукомель. Интеграция мигрантов: вызовы, политика, социальные практики - Мир России. Социология. Этнология. 2011. № 1. Доступ: https://cyberleninka.ru/article/n/ integratsiya-migrantov-vyzovy-politika-sotsialnye-praktiki (проверено 02.07.2021).

3 E. Pain. From protests to pogroms. - OpenDemocracy. 27 August. URL: https://www. opendemocracy.net/en/odr/from-protests-to-pogroms/ (accessed 02.07.2021). 
Южного, а также из Центральной Азии ${ }^{1}$. Следовательно, под понятие «другие» не обязательно подпадают иностранцы в полном смысле этого слова: с таким же успехом они могут быть гражданами России, чьи предки жили здесь с незапамятных времен. Например, выходцы с Северного Кавказа воспринимаются чаще всего именно как мигранты, несмотря на наличие российского гражданства. При этом нужно принимать во внимание и региональные особенности. Хотя Москва этнически более однородна, чем страна в целом, уровни предполагаемых угроз, связанных с мигрантами, не обязательно соответствуют фактическим уровням иммиграции. В других частях страны (этнически) нерусских может быть пропорционально больше, однако они часто являются членами этнических меньшинств с глубокими историческими корнями в России (например, финно-угорские или поволжские и сибирские тюркские этносы). В Москве, напротив, нерусские - это в гораздо большей степени «неграждане», «гастарбайтеры», т.е. в большей степени представители «другого». Тем самым в российском дискурсе мигрант - это носитель культурной идентичности, воспринимаемой как внешняя (чужая) и трудно интегрируемая в русскоцентричное понимание того, кто принадлежит к «своим».

\section{Болевые точки: мигранты как источник преступности}

Действующий мэр С. Собянин баллотировался в качестве представителя действующей власти, однако по ходу кампании он выбрал гораздо более жесткую и популистскую позицию по вопросам миграции, чем официальная кремлевская линия, обращаясь к миграционной проблеме активней, чем любой другой кандидат [Паин 2014] и увязывая ее с проблемами безопасности и благополучием московского населения. Ранее он заявлял, что до $80 \%$ трудовых мигрантов в Москве являются «нелегальными» в том смысле, что у них нет соответствующих разрешений на работу ${ }^{2}$. Он также отмечал высокий уровень преступности среди них: «Если убрать преступления, совершенные не местными жителями (приезжие), то Москва станет самым законопослушным городом в мире» 3 . В своей предвыборной программе он обещал сделать Москву «безопасным городом» путем реализации «эффективной иммиграционной политики» 4 .

Некоторые из кандидатов отличились резкими высказываниями и даже этническими оскорблениями. В агитационных материалах Левичева обнаружились кроссворды со словами «жид» и «нигер» 5 . Кроме того, он утверждал, что $50 \%$ всех преступлений в Москве совершаются не местными жителями: $30 \%$ - выходцами из других регионов России и 20\% - мигрантами из «ближнего зарубежья» 6 . Не делая различия между легальными и нелегальными, внутренними и внешними мигрантами, на протяжении всей кампании он неодно-

1 Ibid.

2 C. Собянин: Трудовая миграция в Москве на $80 \%$ состоит из нелегалов. - АПН. 05.08.2013. Доступ: https://www.apn.ru/index.php?newsid=24638 (проверено 01.07.2021).

3 С. Собянин: Работа мэра интереснее премьерства. - Известия. 13.06.2013. Доступ: https://www.google.com/url?sa=t\&rct=j\&q=\&esrc=s\&source=web\&cd=\&ved=2ahUKEwin3YT Fq97xAhVEpIsKHX6KAc0QFjACegQIBRAD\&url=https\%3A\%2F\%2Fuao.mos.ru\%2Fpresscen ter\%2Fnews\%2Fdetail\%2F775793.html\%3Fspecial\%3DY\%26pdf_file\%3Dy\%26odf_file\%3Dy\& usg=AOvVaw3K7lzoPHeevLTLILM47Rzs (проверено 01.07.2021).

4 Программы кандидатов на пост мэра Москвы. С. Собянин. 17.07.2013. Доступ: https:// www.m24.ru/articles/vybory/17072013/21586 (проверено 04.07.2021).

5 А. Перцев. Слово «жид» есть в словаре. - Gazeta.ru. 06 августа. Доступ: https://www. gazeta.ru/politics/2013/08/06_a_5543917.shtml (проверено 04.07.2021).

${ }^{6}$ Н. Левичев. Программы кандидатов на пост мэра Москвы. 17.07.2013. Доступ: https:// www.m24.ru/articles/vybory/17072013/21586 (проверено 04.07.2021). 
кратно призывал московскую милицию пресекать «этническую преступность». Кандидат от КПРФ Мельников, будучи в рамках официальной интернационалистической идеологии своей партии, тем не менее провозгласил лозунг: «Жесткость и эффективность». Несмотря на традиционное гостеприимство жителей столицы, за последние несколько месяцев преступность, связанная с мигрантами, якобы выросла на 40\%, подрывая рынок труда («дешевая рабская рабочая сила, повышение прибыли грязного бизнеса»), а также «традиции, культуру, язык и дух Москвы и безопасность москвичей» 1.

Навальный, как и ожидалось, присоединился к общей риторике, однако, несмотря на репутацию русского националиста, был на удивление более сдержан. Более того, как отмечает в газете The Moscow Times В. Давидофф, Навальный открыто критиковал лагерь временного содержания для нелегалов, созданный в Москве в июле 2013 г., как незаконный ${ }^{2}$. Однако и он определил нелегальную миграцию как «Питательную среду для насилия и преступности» и призвал к «мониторингу мест компактного проживания мигрантов и предотвращению образования этнических криминальных гетто» 3 .

Единственным кандидатом, который не эксплуатировал тему миграции, был Митрохин из «Яблока», хотя его предвыборный лозунг: «Я верну Москву москвичам» имел двусмысленный характер. Как коренной москвич, он называл Собянина, выходца из Тюмени, варягом и чужаком, навязанным Москве и потому на самом деле не заботящимся о благополучии москвичей. Проблему мигрантов он определил совершенно иначе: «Отвратительны не иммигранты, а расистское отношение к ним, с ними обращаются как со скотом» 4 . Тем не менее и он указал на «огромное количество мигрантов» как на источник «роста националистических настроений и обострения криминогенной ситуации» 5 .

Таким образом, все шесть кандидатов в мэры связывали рост преступности и/или социальной напряженности с иммигрантами. Еще более настораживает то, что большинство кандидатов, как правило, не проводили различия между легальной и нелегальной иммиграцией, просто объединяя всех мигрантов в одну категорию.

\section{Интеграция против ограничений: перспективы преодоления разобщенности}

В ходе дебатов идея интеграции мигрантов уступила место их репатриации, а инклюзивная риторика сменилась более традиционной для популизма эксклюзивной. Так, несмотря на призывы создать специальные центры для детей мигрантов по изучению русского языка 6 , Навальный выступил против предо-

1 И. Мельников. Программы кандидатов на пост мэра Москвы. С. Собянин. Предвыборная программа кандидата в мэры Москвы. 17 июля. Доступ: https://www.m24. ru/articles/vybory/17072013/21586 (проверено 04.07.2021).

2 V. Davidoff. The many myths about Navalny. - Moscow Times. 17.08.2013. URL: https:// www.themoscowtimes.com/2013/08/17/the-many-myths-about-navalny-a26855 (accessed 05.07.2021).

3 А. Навальный. Программы кандидатов на пост мэра Москвы. Программа кандидата в мэры Москвы Алексея Навального: «Измени Россию, начни с Москвы». 17.07.2013. Доступ: https://www.m24.ru/articles/vybory/17072013/21586 (проверено 04.07.2021).

4 С. Митрохин. 2 подхода к борьбе с нелегальной миграцией. - Эхо Москвы. 27.08.2013. Доступ: https://echo.msk.ru/blog/sergei_mitrohin/1144292-еcho/ (проверено 05.07.2021).

5 С. Митрохин. Начнем перемены с Москвы! Программа Сергея Митрохина. Партия «Яблоко». 02.07.2013. Доступ: https://www.yabloko.ru/blog/2013/07/02 (проверено 01.07.2021).

6 Ж. Ульянова. Персональная программа Навального. - Gazeta.ru. 01.07.2013. Доступ: https://www.gazeta.ru/politics/2013/07/01_a_5402685.shtml (проверено 02.07.2021). 
ставления им гражданства и предупредил, что, если такая практика не будет прекращена, «в ближайшие 10-15 лет это приведет нас к некоторым очень проблемным вопросам» 1 . Тем самым он определил пределы интеграции: дети мигрантов должны были адаптироваться к русской культуре, но они не должны были стать будущими гражданами.

Подход Собянина выглядел более гибким. Так, в интервью «Московским новостям» накануне объявления о досрочных выборах он заявил, что хочет, чтобы большинство мигрантов вернулись домой, а если кто-то и должен остаться, то это в первую очередь русофоны с культурой, адекватно отвечающей нашим традициям, т.е. соотечественники. Тем самым, понятие «русофон» предстает не просто лингвистической категорией, а выступает в более широком культурном контексте. В противном случае интеграция невозможна: «Я верю... они должны вернуться в свои семьи, в свои дома, в свои страны», заключил С. Собянин ${ }^{2}$.

Коммунист Мельников изложил свои планы в довольно общих чертах, предложив новой администрации совместно с представителями этнических диаспор разработать план действий по нормализации межэтнических отношений. Однако и здесь провозглашалось «резкое сокращение числа мигрантов», а интеграция - возможностью для немногих: подавляющее большинство мигрантов должны вернуться домой.

Остальные три кандидата вообще прямо не говорили об интеграции мигрантов. Напротив, Дегтярев в одном из теледебатов категорически заявил, что «в Москве не должно быть мигрантов, ни легальных, ни нелегальных»: «Всех надо вывезти из Москвы... Москве нужен русский мэр. Москва - российская столица Российского государства (русская столица русского государства)» 3 . Левичев и Митрохин остались в рамках необходимости соблюдения законодательства, пообещав бороться с нелегальной миграцией и жестко наказывать тех, кто использует нелегальную рабочую силу. В программной статье «Из мегаполиса мигрантов в город граждан» Левичев утверждал, что нынешняя ситуация «невыносима» и что «необходимо ужесточить уголовную ответственность федеральных и городских чиновников, предпринимателей и подрядчиков за трудоустройство нелегалов, а также сотрудников правоохранительных органов, прикрывающих этот произвол» ${ }^{4}$. Митрохин пообещал наказать всех, кто использует нелегальный «рабский труд», начиная с самой городской администрации ${ }^{5}$.

Таким образом, кандидаты были единодушны в необходимости радикального сокращения числа мигрантов в столице. С. Собянин даже выступил с опровержением идеи о том, что Москва зависит от мигрантов из Средней Азии для выполнения черной, низкооплачиваемой работы: «Официально Москве

${ }^{1}$ А. Навальный. Интервью: «Миграция». - Эхо Москвы. 23.08.2013. Доступ: https://echo. msk.ru/programs/beseda/1139878-echo/ (проверено 02.07.2021).

2 А. Богомолов, А. Николаева. Нужны и демократия, и власть. - Московские ведомости. 30.05.2013. Доступ: https://www.mn.ru/moscow_authority/20130530/347635870.html (проверено 08.09.2021).

3 Девятый раунд дебатов начался на телеканале «Москва Доверие». - Телеканал «Москва 24». 30.08.2013. Доступ: https://www.m24.ru/articles/vybory/30082013/24630 (проверено $30.06 .2021)$.

${ }^{4}$ Н. Левичев. Программы кандидатов на пост мэра Москвы. 17.07.2013. Доступ: https:// www.m24.ru/articles/vybory/17072013/21586 (проверено 04.07.2021).

5 С. Митрохин. Чем я отличаюсь от других кандидатов. - Эхо Москвы. 05.09.2013. Доступ: https://echo.msk.ru/blog/sergei_mitrohin/1150774-echo/ (проверено 03.07.2021). 
нужно всего 200 тыс. мигрантов из-за рубежа, - заявил он, - на самом деле их в два-три раза больше» 1 .

Однако для такого сокращения репатриация не является решением, если она не сопровождается параллельными усилиями по сдерживанию притока новых иммигрантов. Для достижения этой цели кандидаты предложили ужесточить режим въезда и сделать менее привлекательным использование иностранной рабочей силы. Известно, что граждане многих стран СНГ освобождены от необходимости получения визы для посещения России на срок до 90 дней, путешествуя по национальному удостоверению личности (внутреннему паспорту). Эту практику нужно было бы прекратить, утверждал Собянин, и «как можно скорее перейти на заграничные паспорта, чтобы люди появлялись на границе не с бумажкой, а с настоящими паспортами, позволяющими идентифицировать этих граждан» ${ }^{2}$.

Навальный пошел еще дальше: предполагаемые мигранты должны не только иметь заграничный паспорт, но и получать визу. Паспорта можно легко купить или подделать, утверждал он, и поэтому единственный способ контролировать поток иммигрантов - это ввести визовый режим для стран, которые предоставляют большую часть трудовых мигрантов ${ }^{3}$.

Мельников занял более умеренную позицию, категорически отвергнув необходимость визового режима для поездок между бывшими советскими республиками, заявив, что «это создаст совершенно ненормальную ситуацию» ${ }^{4}$. Вместо этого он предложил ввести рабочие визы для граждан СНГ, а также запустить «комплексную программу замещения иностранной рабочей силы российскими гражданами», утверждая, что около 3 млн российских граждан в европейской части страны готовы взять на себя работу, которую сейчас выполняют мигранты. Чтобы облегчить переориентацию на местную рабочую силу, работодатели должны платить более высокие взносы социального страхования при найме рабочей силы мигрантов, чем при найме российских граждан, предложил он.

М. Дегтярев в очередной раз же придерживался наиболее радикальных взглядов: он предложил ввести запрет на работу иностранных граждан в розничной торговле, т.е. там, где мигранты традиционно были чрезмерно представлены.

\section{Предвыборная борьба в рамках иммигрантской проблематики}

Таким образом, кандидаты в мэры Москвы выступили за введение радикальных мер по регулированию миграции, а те, которых можно обвинить в «мягком отношении к миграции», находились в невыгодном положении. Особенно уязвимым в этом отношении оказался действующий мэр Собянин, занимавший свой пост уже почти 3 года и несший ответственность за решение вопросов, связанных с миграцией. Так, партия «Национал-либеральный демократический выбор», которая не выставила своего кандидата, но призвала избирателей поддержать либо Навального, либо Митрохина, обрушилась с критикой на «неумелую миграционную политику Собянина». Якобы за годы его нахожде-

1 Собянин подсчитал, какое количество трудовых мигрантов нужно Москве. Интерфакс. 22.08.2013. Доступ: https://www.interfax.ru/russia/324732 (проверено 02.07.2021).

2 Л. Проценко. Вести от Сергея Собянина. - Российская газета. 07.07.2013. Доступ: https://rg.ru/2013/07/07/intervie-site.html (проверено 02.07.2021).

3 Р. Ошаров. Навальный обещает сократить количество мигрантов на $70 \%$. Голос Америки. 31.08.2013. Доступ: https://www.golosameriki.com/a/moscow-election/1740986.html (проверено 02.07.2021).

${ }^{4}$ И. Мельников. Интервью: «Миграция». - Эхо Москвы. 04.09.2013. Доступ: https://echo. msk.ru/programs/beseda/1148686-еcho/ (проверено 28.06.2021). 
ния на посту число мигрантов в Москве выросло на 50\%: «Они способствовали высокому уровню преступности, распространению инфекционных заболеваний и коррупции среди городских служащих и домовладельцев, эксплуатировавших незадачливых соискателей». Действующему мэру пришлось позиционировать себя «жестким по отношению к мигрантам». Для этого ему пришлось даже раздвинуть границы допустимого и политкорректного. Так, он заявил, что он не приветствует будущую интеграцию мигрантов, плохо знающих русский язык, - сообщение, которое противоречило даже позиции Путина, высказанной в ходе предвыборной кампании годом ранее.

Однако, несмотря на эти заявления, конкуренты поставили под сомнение решительность Собянина в отношении мигрантов, напоминая, например, об аресте 1200 вьетнамских граждан, работавших на подпольной швейной фабрике. Митрохин охарактеризовал всю операцию как «жалкую попытку Собянина проявить некоторую решительность», поскольку это всего лишь капля в море, которая не решает реальной проблемы: разоблачения людей, которые нанимают нелегальных трудовых мигрантов или помогают им попасть в Москву без необходимых документов. По его мнению, главная причина, по которой дела таких людей не расследовались, была ясна: " “миграционная мафия” имела глубоко укоренившиеся связи в коридорах власти» ${ }^{1}$.

Также Митрохин пытался разыграть миграционную карту и против Навального, с которым они боролись за голоса либерально настроенной интеллигенции. Митрохин разоблачал его вопиющее злоупотребление статистическими данными: Навальный в интервью «Эхо Москвы» настаивал на том, что $50 \%$ всех преступлений в Москве совершаются «мигрантами из-за границы», хотя официальная статистика показывает не более $20 \% 2$. «Что это, как не популистское и безответственное заигрывание с ксенофобскими настроениями?» - писал Митрохин ${ }^{3}$. Запись в блоге была проиллюстрирована фотографией Навального, позирующего вместе с несколькими организаторами «Русского марша», в т.ч. Александром Беловым (Поткиным), бывшим лидером ДПНИ, который был неприемлемой фигурой для большинства либеральной интеллигенции.

При этом для Навального было важно обратиться как к националистическому, так и к либеральному электорату и не потерять поддержку ни того ни другого. Он мог быть уверенным за националистический электорат, где его репутация была довольно прочной. Так, информационное агентство «Национальная служба новостей» $(\mathrm{HCH})$ в рамках мониторинга искренности кандидатов в отношении националистической идеологии назвало Навального единственным кандидатом, прошедшим данный тест. Напротив, «слова Собянина о необходимости обуздать миграцию, которую он сам поощрял и мог остановить в любой момент, звучат - по мнению агентства - как жестокая насмешка над москвичами» ${ }^{4}$. Сложнее обстояло дело с либералами. Если бы Навальный слишком активно поднял антииммиграционный вопрос, он мог бы легко потерять часть избирателей - они проголосовали бы скорее всего за Митрохина.

1 Сергей Митрохин: Миграционный пиар Собянина. - Партия «Яблоко». 13.08.2013. Доступ: https://www.yabloko.ru/blog/2013/08/13 (проверено 29.06.2021).

2 А. Навальный. Интервью: «Миграция». - Эхо Москвы. 23.08.2013. Доступ: https://echo. msk.ru/programs/beseda/1139878-echo/ (проверено 02.07.2021).

3 С. Митрохин. Чем я отличаюсь от других кандидатов. - Эхо Москвы. 05.09.2013. Доступ: https://echo.msk.ru/blog/sergei_mitrohin/1150774-echo/ (проверено 03.07.2021).

4 Стоит ли националистам голосовать за Навального? Плюсы и минусы Навального. Оригинал: НСН. 30.07.2013. Доступ: https://basmanov.livejournal.com/2129111.html (проверено 03.07.2021). 
Мария Гессен считает, что «впадение Навального в ксенофобскую риторику оттолкнуло небольшую часть оппозиции, но, вероятно, завоевало ему гораздо больше сторонников» [Gessen 2013]. Хотя более внимательное изучение его предвыборных заявлений позволяет предположить, что он полностью осознавал эту ситуацию и сделал преднамеренную и довольно успешную попытку представить программу, которая была бы приемлема и для либералов.

Так, по некоторым вопросам предвыборной кампании Собянин занимал более антииммигрантскую позицию, чем предполагаемый националист Навальный. Стратегия же Митрохина по привлечению голосов либерального среднего класса имела свои неизбежные ограничения, принимая во внимание наличие антииммигрантских настроений, имевших место как раз среди указанного электората. В явной попытке компенсировать это некоторые нападки Митрохина на Собянина были сформулированы довольно ксенофобски. Именно так можно интерпретировать обвинения городских властей в «открытии шлюзов» для Москвы, допущении притока огромных волн нелегальной миграции, что привело к «превращению Москвы из столицы России в среднеазиатскую провинцию» .

\section{Заключение}

Подводя итог, следует отметить, что все партии не досчитались своих избирателей. Попытки Митрохина от «Яблока», традиционной российской либеральной партии, выйти на антимиграционную тематику фактически окончились ничем и не смогли повлиять на столичный электорат: его 3,5\% голосов - меньше половины того, что «Яблоко» набрало в Москве на выборах в Государственную думу 2011 г. Не лучше обстояли дела и у кандидатов от системной оппозиции: Мельников набрал 10,7\% (КПРФ-19,3\% в 2011 г.), М. Дегтярев - 2,9\% (ЛДПР - 9,4\% в 2011 г.), Н. Левичев - 2,8\% («Справедливая Россия» - 12,1\% в 2011 г.).

Во многом это связано с появлением на политическом поле новой фигуры Алексея Навального. Его 27,2\% голосов стали результатом непривычного сочетания либеральных и националистических взглядов, что, безусловно, расширило его электоральную базу. В сочетании с эффективной по многим критериям избирательной кампанией это позволило мобилизовать большинство протестного электората. Наконец, его основному конкуренту Сергею Собянину удалось набрать необходимые 51,4\% голосов, чтобы избежать непредсказуемого второго тура, получив электоральное одобрение со стороны населения.

В ходе кампании большинство кандидатов обозначили антииммигрантскую риторику как выходящую за рамки узко проблемного понимания вопроса. Фактически предвыборные нарративы затронули образ мигранта в рамках дискурса идентичности с четким антагонистическим противопоставлением «своего» и «другого» как находящегося за пределами российского национального проекта. В этом контексте использование популистской риторики помогло сформулировать политические месседжи, адресованные избирателям. Логика предвыборной гонки заставляла кандидатов расширять границы дозволенного и даже политически корректного. В этой связи можно говорить о наличии популистских черт у всех ее участников. Другое дело, что масштаб отдельно взятого столичного мегаполиса не позволил сформулировать их позиции с точки зрения очевидного популизма. В отличие от общенационального контекста, многие понятия, отражающие политику идентичности, выражены более слабо и не позволяют поставить идеологию во главу угла. Не удивительно, что два лидирующих кандидата сочетали в своих стратегиях идеологическую риторику с ответами на практические вопросы миграционной политики. 


\title{
Список литературы
}

Воронков К.В. 2012. Алексей Навальный: Гроза жмуликов и воров. М.: ЭксмоПресс. 224 c.

Паин Э. 2014. Ксенофобия и национализм в эпоху российского безвременья. - Pro et Contra. T. 62. № 1-2. C. 34-53.

Canovan M. 1999. Trust the People! Populism and the Two Faces of Democracy. Political Studies. Vol. 47. Is. 1. P. 2-16.

Gessen M. 2013. The Mad Race for Moscow Mayor. - New York Times. 12.08. URL: https://latitude.blogs.nytimes.com/2013/08/12/the-mad-race-for-moscowmayor/ (accessed 08.09.2021).

Golosov G. 2013. Navalny Steps into the Ring. - OpenDemocracy. 19.07. Доступ: https://www.opendemocracy.net/en/odr/navalny-steps-into-ring/ (проверено 08.09.2021).

Laclau E. 2005. On Populist Reason. London: Verso. 276 p.

Rydgren J. 2006. From Tax Populism to Ethnic Nationalism: Radical Right-Wing Populism in Sweden. N.Y., Oxford: Berghahn Books. 160 p.

Taggart P. 2004. Populism and Representative Politics in Contemporary Europe. Journal of Political Ideologies. Vol. 9. Is. 3. P. 269-288.

BARANOVA Tatyana Vladimirovna, postgraduate student at the Chair of History and Theory of International Relations, Lobachevsky State University of Nizhny Novgorod (2 Ul'yanova St, Nizhny Novgorod, Russia, 603950; sky-ellize@yandex.ru)

KRIVOV Sergey Valer'evich, Cand.Sci. (Pol.Sci.), Associate Professor at the Chair of Political Science, Lobachevsky State University of Nizhny Novgorod (2 Ul'yanova St, Nizhny Novgorod, Russia, 603950; skrivov2@yandex.ru) USTINKIN Sergey Vasilyevich, Dr.Sci. (Hist.), Professor; Director of the Volga Branch of the Federal Center of Theoretical and Applied Sociology, Russian Academy of Sciences (4 Holodny Lane, Nizhny Novgorod, Russia, 603000); Head of the International Cross-Disciplinary Laboratory for Studies of Global and Regional Sociopolitical Processes, Scientific Director of the Higher School of International Relations and World Politics, Dobroljubov State Linguistics University of Nizhny Novgorod (31a Minina St, Nizhny Novgorod, Russia, 603155); sv.ustinkin@gmail.com)

\section{MIGRATION IN THE DISCOURSE OF THE 2013 ELECTION CAMPAIGN: POPULISM OR IDEOLOGICAL TRANSFORMATION?}

\begin{abstract}
The article examines the campaign for the election of the mayor of Moscow in 2013 from the point of view of the use by its participants in the course of the election race of the techniques and methods of populist discourse. As a research method, the authors use discursive approach of E. Laclau aimed at identifying the basic indicators of populist rhetoric, including the antagonistic opposition of "we» and "others", as well as identifying the qualitative characteristics of the populist narrative. The analysis of these materials allows making conclusions about the strengthening the populist rhetoric in the Russian political discourse against the background of a drop in the electoral results of candidates representing traditional Russian parties and ideological platforms. At the same time, the authors indicate that this trend is due to the shift of the ideological spectrum on the Russian political scene. The paper concludes that the extension of the capital urban area, in contrast to the national context, did not allow switching to ideological rhetoric completely. As a result of this, both the main competitors Sobyanin and Navalny actually relied on the electoral potential of both the current government and the powerful protest movement against the background of the dissatisfaction of the metropolitan voter with the peculiarities of the political system of the Russian Federation.
\end{abstract}

Keywords: populism, identity discourse, immigration, electoral campaign, electorate 